\title{
SISTEM INFORMASI LACAK BALAK BERDASARKAN SKEMA COC LEMBAGA EKOLABEL INDONESIA (LEI)
}

\author{
Yohanes Priadi Wibisono \\ Program Studi Sistem Informasi Universitas Atma Jaya Yogyakarta \\ Jln. Babarsari 43 Yogyakarta \\ e-mail : yohanes priadi@mail.uajy.ac.id
}

\begin{abstract}
World public awareness of the importance of forest conservation cause market demand for the legality of timber or timber products certified in the timber industry. LEI (Indonesia Ecolabelling Institute) as an independent institution which is a non-profit organization based constituent developing forest certification systems. Chain of custody system plays an important role in running the scheme CoC (Chain of Custody) for LEI. System development methods in this study using the FAST (Framework for the Application of Systems Techniques). As a constituent based organization LEl retains independence and transparency, both necessary for the credibility of forest certification. Chain of custody system is expected to accommodate the needs and desires of the market against the legality of timber and also assist the government in implementing SVLK (Timber Legality Verification Standard)
\end{abstract}

Keywords : Chain of Custody, certification, timber legality, FAST (Framework for the Application of Systems Techniques).

\begin{abstract}
Abstrak
Kesadaran masyarakat Dunia akan pentingnya kelestarian hutan menimbulkan permintaan pasar terhadap legalitas kayu atau produk kayu yang bersertifikasi dalam industri kayu. LEI (Lembaga Ekolabel Indonesia) sebagai salah satu lembaga independent yang merupakan organisasi berbasis non-profit konstituen mengembangkan sistem sertifikasi hutan. Sistem lacak balak memegang peranan penting dalam menjalankan skema CoC (Chain of Custody) bagi LEl. Metode pengembangan sistem dalam penelitian ini menggunakan FAST (Framework for the Application of Systems Techniques). Sebagai organisasi berbasis konstituen, LEI mempertahankan kemerdekaan dan transparansi, baik yang diperlukan untuk kredibilitas sertifikasi hutan. Sistem lacak balak diharapkan dapat mengakomodasikan kebutuhan serta keinginan pasar terhadap legalitas kayu dan juga membantu pemerintah dalam mengimplementasi SVLK ( Standard Verifikasi Legalitas Kayu )
\end{abstract}

Kata Kunci : lacak balak, serifikasi, legalitas kayu, FAST (Framework for the Application of Systems Techniques).

\section{PENDAHULUAN}

Penyediaan sistem informasi sebagai pendukung proses suatu organisasi merupakan sesuatu yang mutlak. Pesatnya perkembangan Teknologi Informasi khususnya internet, memungkinkan pengembangan layanan informasi yang lebih baik dalam suatu organisasi. Prinsip-prinsip sistem informasi dalam sebuah organisasi adalah penggunaan sistem informasi pada sebuah organisasi yang bertujuan untuk menambah nilai bagi organisasi tersebut sangat dipengaruhi oleh struktur organisasi, budaya dan perubahan [Stair, 2010]. Sistem informasi didefinisikan oleh Robert A. Leitch dan K. Roscoe Davis sebagai sistem di dalam suatu organisasi yang mempertemukan kebutuhan pengelohan transaksi harian, mendukung operasi, bersifat manajerial dan kegiatan strategi dari suatu organisasi dan menyediakan pihak luar tertentu dengan laporan-laporan yang diperlukan (Dikutip didalam buku Jogiyanto, 2005, hal.11).

Dalam menghadapi permintaan pasar internasional mengenai legalitas kayu dalam industi kayu, Pemerintah telah mengeluarkan Sistem Verifikasi Legalitas Kayu (SVLK) melalui PermenLHK NOMOR : P.30/Menlhk/Setjen/PHPL.3/3/2016, yang mengatur mengenai tata cara verifikasi legalitas kayu. Dalam PermenLHK tersebut, disebutkan bahwa setiap industri yang mengelola hasil hutan (kayu) wajib mendapatkan sertifikat SVLK. Jika industri sudah mengantongi sertifikat 
legalitas kayu ini, maka bisa dipastikan bahwa sumber bahan baku yang dipakai adalah legal/sah.

Berdasarkan kegiatan LEI (Lembaga Ekolabel Indonesia) dalam memperkuat organisasi masyarakat sipil dan industri kayu kecil dan menengah dalam Implementasi SVLK ( Sistem Verifikasi Legalitas Kayu ) di Jawa, ditemukan bahwa petani hutan tidak mendapatkan informasi dengan baik dan kurangnya kapasitas untuk melaksanakan SVLK. Meskipun industri kayu telah diinformasikan dengan baik dan beberapa dari mereka sudah menerapkan SVLK, tetapi industri sulit untuk menemukan kayu yang disertifikasi oleh salah satu lembaga sertifikasi wajib ( SVLK ) atau standar sertifikasi sukarela ( FSC atau LEI ). Pemerintah dalam hal ini melalui Kementerian Lingkungan Hidup dan Kehutanan telah mengimplementasikan SVLK untuk dapat melacak dan untuk memastikan legalitas sumber kayu yang beredar dan diperdagangkan di Indonesia. Implementasi SVLK dilakukan untuk melaksanakan peraturan pemerintah yang berlaku terkait perdagangan dan peredaran hasil hutan di Indonesia. SVLK menjadi syarat mutlak untuk dapat masuk pada perdagangan Internasional dan berlaku sebagai pengganti fleg license.

Chain of Custody ( $\mathrm{CoC})$ adalah prosedur atau sistem penelusuran satu langkah ke belakang atau simpul yang dilewati oleh suatu produk sampai ke sumber bahan bakunya dimana setiap langkah memiliki bukti dokumentasi. Menurut G. Giova [1], lacak balak adalah Prosedur untuk melakukan dokumentasi sebagai bukti kronologis dari suatu peristiwa. Sementara itu menurut J. Ćosić, Z. Ćosić [2], CoC adalah bagian yang sangat penting dan paling rentan dari proses penyidikan yang akan memastikan bukti dapat diterima atau tidak.

LEI juga menemukan bahwa sebagian besar kayu dari hutan rakyat sulit ditelusuri ke tunggul asli. Ini terjadi karena pelaku industri kayu tidak mencatat asal hutan di mana kayu-kayu yang dipanen. Akibatnya, dokumentasi kayu tidak dicatat dengan baik. Salah satu kegiatan LEl juga bertujuan untuk mengatasi kekurangan pasokan kayu dari hutan swasta / komunitas / hutan rakyat yang telah diverifikasi untuk industri kayu. Penelitian ini dimaksudkan untuk membuat jelas dan transparan rantai kayu dari hutan rakyat ke industri. Pelaku industri kayu akan diberdayakan melalui pelatihan tentang legalitas kayu dan lacak balak sehingga catatan dokumentasi kayu akan dilaksanakan dengan benar.

Belajar dari permasalahan ini, ada kebutuhan untuk mengembangkan sistem informasi lacak balak untuk mengembangkan jaringan hutan rakyat serta Industri kecil-menengah dalam rangka menjalankan praktek legalitas dan pengelolaan hutan lestari.

\section{METODE PENELITIAN}

Pengumpulan data yang digunakan dalam penelitian ini adalah dengan mengumpulkan data primer yang dikumpulkan secara langsung dari objek yang diteliti yaitu Lembaga Ekolabel Indonesia (LEI) dengan cara Observasi, yaitu teknik pengumpulan data dengan mengadakan pengamatan secara langsung pada objek yang diteliti. Yang kedua adalah dengan wawancara, yaitu mengadakan komunikasi langsung dengan pengguna yang terlibat dengan objek yang diteliti.Selain itu peneliti juga mengumpulkan data sekunder dengan mempelajari data yang ada di perpustakaan, referensi buku, dokumen-dokumen, bukubuku prosedur yang berhubungan dengan maksud dan tujuan penelitian.

Dalam melakukan pengembangan sistem, penulis menggunakan metode FAST (Framework for the Application of Systems Techniques) dengan pendekatan prototyping.

Menurut Whitten (2000:183) :

Seperti kebanyakan metodologi komersial, metodologi FAST hipotesis kita tidak menggunakan pendekatan tunggal pada analisis sistem. Malahan ia mengintegrasikan semua pendekatan populer yang diperkenalkan pada paragraph-paragraf terdahulu kedalam satu kumpulan agile method / metode cerdas.

Dari pernyataan diatas jelaslah bahwa metode FAST menggunakan banyak pendekatan dalam analisis sistem yang merupakan pendekatan populer, sehingga dengan demikian hasil analisis 
yang diharapkan akan lebih tajam dan akurat. FAST dapat dikatakan best practice dari metodologi-metodologi terdahulu.

Output dari metodologi pengembangan mana pun adalah solusi bisnis yang dapat membantu memecahkan masalah, peluang, dan lain-lain. Metodologi FAST (Abdullah, 2013) adalah salah satu metode pengembangan sisteminformasi dengan urutan langkahnya adalah Scope Definition (lingkup definisi) - Problem Analysis (Analisis Permasalahan) - Requirement Analysis (Analisis Kebutuhan) - Decision Analysis (Analisis Keputusan) - Logical Design (Desain Logis) - physical Design \& Integration (Desain Fisik dan Integrasi) - Construction \& Testing - Installation \& Delivery. Adapun fase-fase tersebut adalah sebagai berikut :

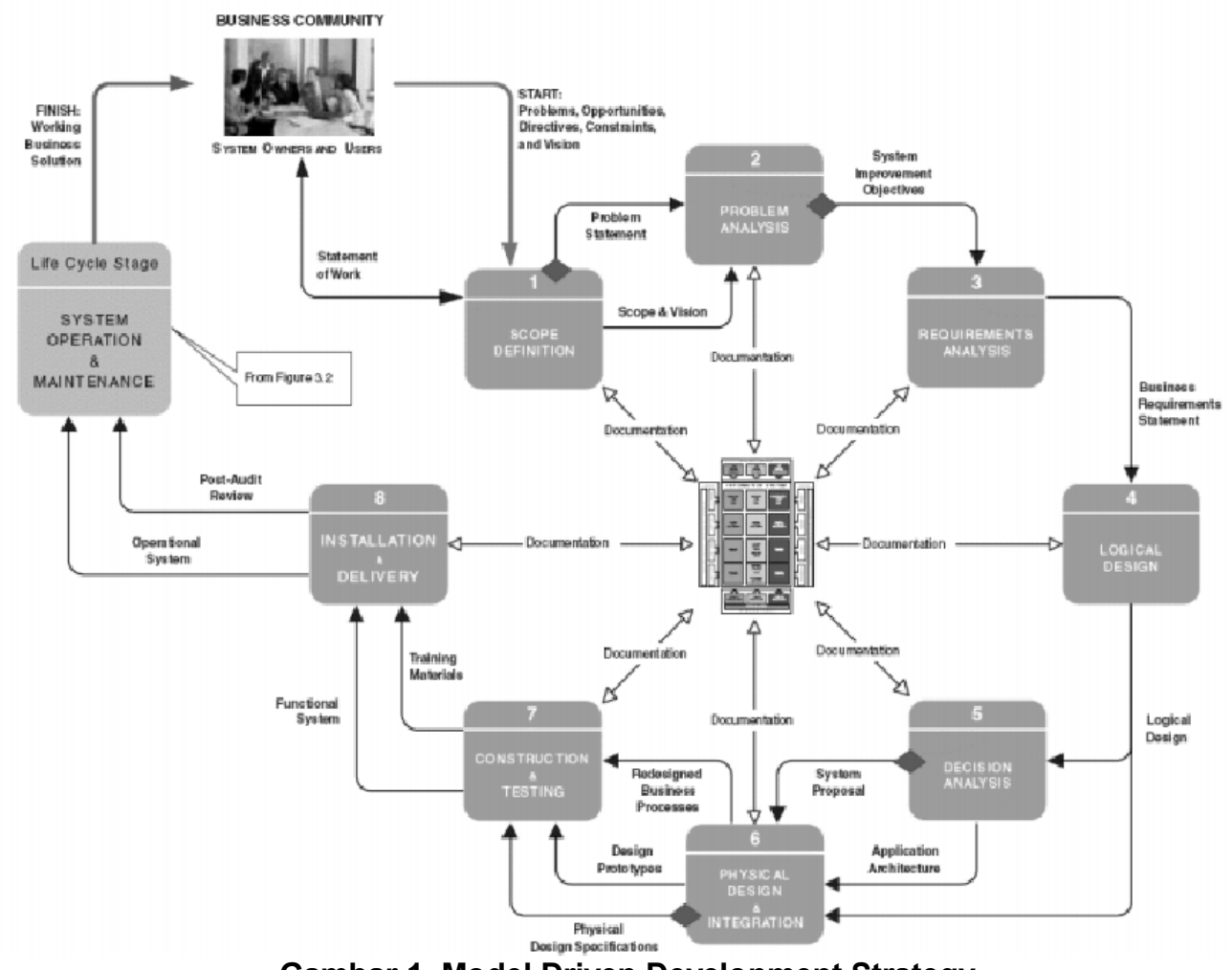

Gambar 1. Model Driven Development Strategy

Penulis memilih metode FAST dengan pendekatan prototyping berdasarkan beberapa pertimbangan :

1. Pendekatan Prototyping banyak melibatkan user, sehingga dapat meningkatkan visibilitas sistem dan dapat mendapat dukungan lebih dari user dan pihak managemen.

2. Pendekatan Prototyping lebih cepat, lebih murah, dan tidak memerlukan tim pengembang dalam ukuran besar. Faktor-faktor ini menyebabkan pendekatan prototyping sesuai dengan sistem berukuran sedang, seperti sistem yang akan di kembangkan ini.

3. Pendekatan Prototyping dapat memudahkan user mengetahui keinginan mereka. Dalam prototyping, sistem terdiri dari beberapa siklus, dimana pada tiap siklus tim pengembang menghasilkan suatu prototipe yang akan dicoba user. Kemudian user akan megevaluasi kekurangan prototipe tersebut. Hasil evaluasi ini akan dianalisa kembali oleh tim pengembang dan kemudian menghasilkan prototipe yang baru. Demikian siklus ini akan berlangsung terus sampai didapat sistem yang sesuai dengan keinginan user. 


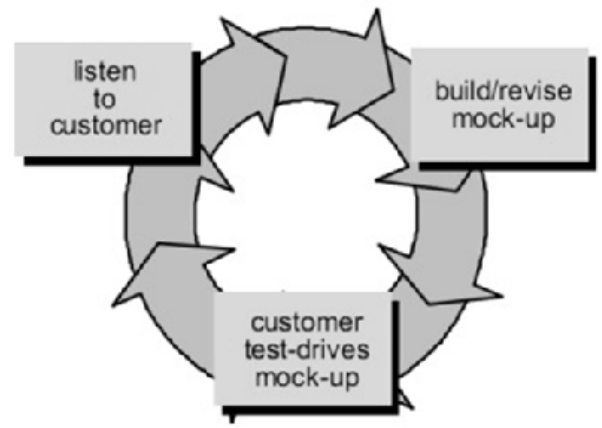

Gambar 2. Siklus Prototyping

Sumber : ( Pressman, 2002:40)

\section{HASIL DAN PEMBAHASAN}

\section{Permasalahan}

Berdasarkan hasil observasi dan wawancara dengan LEI dan pelaku industri kayu, ada beberapa masalah yang muncul seperti yang terlampir pada tabel berikut:

Tabel 1. Hasil Observasi dan Wawancara: Permasalahan dan Solusi yang diharapkan

\begin{tabular}{|c|c|c|}
\hline No & $\begin{array}{l}\text { Pernyataan Singkat dari } \\
\text { Masalah atau Peluang }\end{array}$ & Solusi yang ditawarkan \\
\hline 1 & $\begin{array}{l}\text { Industri Kecil dan Menengah di } \\
\text { berbagai daerah kesulitan } \\
\text { mendapatkan pasokan kayu legal / } \\
\text { terverifikasi / bersertifikasi dan } \\
\text { mengetahui jatah tebang hutan } \\
\text { rakyat }\end{array}$ & $\begin{array}{l}\text { Pengembangan system yang bias di akses } \\
\text { melalui internet sehingga industri bisa langsung } \\
\text { mengetahui ketersediaan kayu hutan rakyat }\end{array}$ \\
\hline 2 & $\begin{array}{l}\text { Proses pengolahan data, laporan } \\
\text { berkas kayu kurang efektif dan } \\
\text { efisien pada setiap simpul / pelaku } \\
\text { industri kayu }\end{array}$ & $\begin{array}{l}\text { Adanya integrasi data untuk semua laporan dan } \\
\text { data disimpan dalam basis data sehingga } \\
\text { pemanggilan dan pemrosesan data menjadi } \\
\text { lebih mudah pada setiap simpul }\end{array}$ \\
\hline 3 & Akurasi data & $\begin{array}{l}\text { Adanya basis data yang terintegrasi dengan } \\
\text { Primary key sehingga penginputan data yang } \\
\text { sama tidak akan terjadi pengulangan / } \\
\text { redudansi data }\end{array}$ \\
\hline
\end{tabular}

\section{Simpul atau Pelaku Industri Kayu}

Berdasarkan pengelompokan yang dilakukan LEI, simpul-simpul dapat terbagi ke dalam tiga rute, Rute 0 merupakan simpul antara hutan ke tempat pengumpulan kayu di hutan atau Unit Manajemen Hutan Rakyat (UMHR). Rute 1 merupakan simpul-simpul yang berada antara hutan atau pengumpulan kayu ke pembeli pertama atau pintu masuk industri seperti contohnya TPT KB, Primer, TPT KO. Rute 2 merupakan simpul-simpul yang berada di dalam industri hasil hutan. 


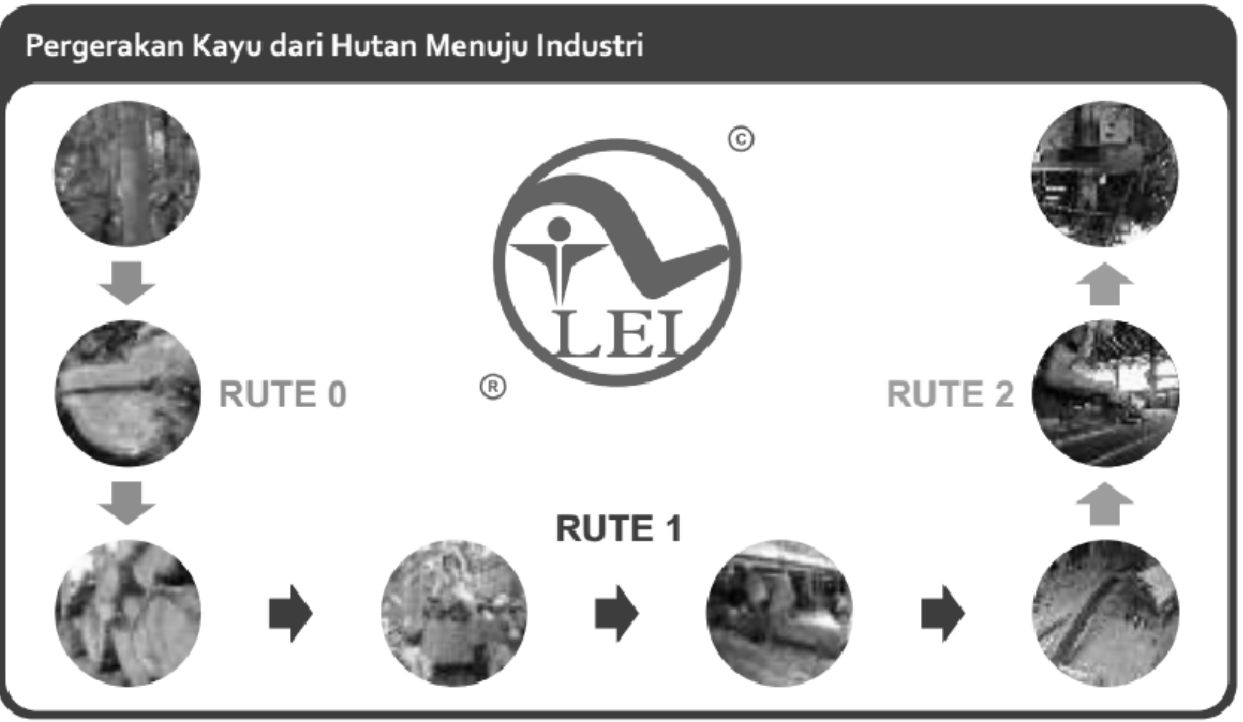

Gambar 3. Alur Pergerakan Kayu

Simpul-simpul tersebut dinilai dalam sertifikasi lacak balak. Penelusurannya mulai dari Industri Kecil Menengah (IKM), Industri Rumah Tangga (IRT), Tempat Penampungan Terdaftar Kayu Olahan (TPT KO), Primer ( tempat penggergajian kayu / sawmill), Tempat Penampungan Terdaftar Kayu Bulat (TPT KB), Unit Manajemen Hutan Rakyat (UMHR), Petani Hutan Rakyat, Sampai ke lokasi pangkal pohon.

\section{Analisa Proses Bisnis}

Berdasarkan masalah yang telah dikemukakan diatas telah dibuatkan skema Alur verifikasi legalitas lacak balak berdasarkan CoC (Chain of Custody / Rantai Pengawasan) oleh LEI (Gambar 4.). Lacak Balak atau Chain Of Custody (CoC) adalah kronologis pendokumentasian barang bukti, dari mulai di temukan di TKP hingga penduplikasian dan penyimpanannya baik secara fisik ataupun digital [3]. Dengan kata lain, industri harus mampu membuktikan bahwa bahan baku yang diterima berasal dari sumber yang sah, menerapkan sistem penelusuran kayu, dan memenuhi persyaratan jika proses pengolahan produk melakui jasa dengan pihak lain.

Keterlacakan antar simpul dapat diketahui melalui dokumen Nota angkut dimana pada dokumen tersebut terdapat asal produk (kayu / olahan kayu) dan tujuan pengiriman produk. Sehingga Nota Angkut menjadi kunci dalam rantai penelusuran produk.

\section{Cause-Effect Analysis \& System Improvement Objective}

Setelah memahami ruang lingkup (scope), permasalahan (problem), dan peluang (opportunity) dari sistem yang ada, maka dapat dibangun suatu perbaikan terhadap sistem tersebut ditunjukkan dalam Tabel 2. 


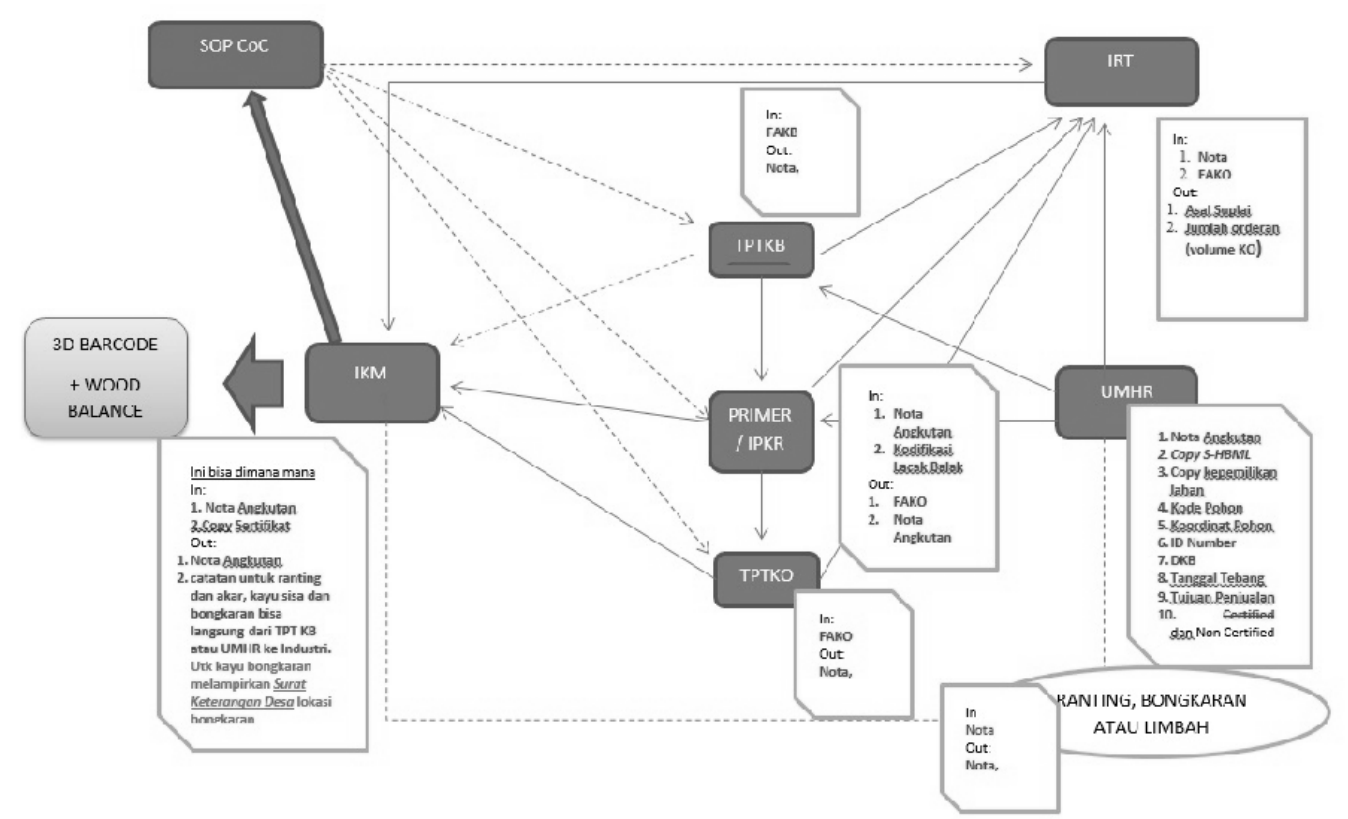

Keterangan Skema:

Gambar 4. Skema CoC LEI

$\begin{array}{ll}\text { UMHR } & \text { : Unit Manajemen Hutan Rakyat } \\ \text { TPT KB } & : \text { Tempat Penampungan Terdaftar Kayu Bulat } \\ \text { Primer } & : \text { Tempat Penggergajian Kayu } \\ \text { TPT KO } & : \text { Tempat penampungan Terdaftar Kayu Olahan } \\ \text { IKM } & : \text { Industri Kecil Menengah } \\ \text { IRT } & : \text { Industri Rumah tangga }\end{array}$

Tabel 2. Cause-Effect Analysis \& System Improvement Objective

\begin{tabular}{|c|c|c|c|}
\hline \multicolumn{2}{|c|}{ CAUSE AND EFFECT ANALYSIS } & \multicolumn{2}{|c|}{ SYSTEM IMPROVEMENT OBJECTIVES } \\
\hline $\begin{array}{l}\text { Problem or } \\
\text { Opportunity }\end{array}$ & $\begin{array}{l}\text { Causes and } \\
\text { Effects }\end{array}$ & System Objectives & $\begin{array}{c}\text { System } \\
\text { Constraint }\end{array}$ \\
\hline $\begin{array}{l}\text { Industri Kecil dan } \\
\text { Menengah kesulitan } \\
\text { mendapatkan } \\
\text { pasokan kayu legal } \\
\text { dan mengetahui jatah } \\
\text { tebang hutan rakyat }\end{array}$ & $\begin{array}{l}\text { IKM terhambat } \\
\text { mendapatkan } \\
\text { pasokan kayu } \\
\text { legal untuk } \\
\text { memenuhi } \\
\text { permintaan pasar }\end{array}$ & $\begin{array}{l}\text { 1. Meningkatkan } \\
\text { sistem } \\
\text { manajemen kayu } \\
\text { legal } \\
\text { 2. Mempermudah } \\
\text { IKM dalam } \\
\text { mengetahui } \\
\text { ketersediaan } \\
\text { kayu legal dan } \\
\text { jatah tebang dari } \\
\text { petani hutan } \\
\text { rakyat / UMHR }\end{array}$ & $\begin{array}{l}\text { 1. Sistem harus } \\
\text { mempermudah IKM } \\
\text { dalam pencariaan } \\
\text { stock kayu legal siap } \\
\text { produksi } \\
\text { 2. Sistem harus dapat } \\
\text { menampung data } \\
\text { kayu legal dari setiap } \\
\text { simpul yang } \\
\text { termasuk dalam CoC } \\
\text { LEI }\end{array}$ \\
\hline $\begin{array}{l}\text { Proses pengolahan } \\
\text { data, laporan berkas } \\
\text { kayu di setiap simpul } \\
\text { kurang efektik dan } \\
\text { efisien }\end{array}$ & $\begin{array}{l}\text { Proses } \\
\text { pengolahan data } \\
\text { untuk laporan } \\
\text { sebagian } \\
\text { dilakukan dua kali } \\
\text { proses }\end{array}$ & $\begin{array}{l}\text { 1. Adanya integrasi } \\
\text { data antar simpul } \\
\text { untuk semua } \\
\text { laporan dan data } \\
\text { disimpan dalam } \\
\text { basis data } \\
\text { sehingga }\end{array}$ & $\begin{array}{ll}\text { 1. } & \text { Sistem yang baru } \\
\text { diharapkan dapat } \\
\text { mengurangi biaya } \\
\text { operasional seperti } \\
\text { pemakaian kertas } \\
\text { dalam pencetakan } \\
\text { laporan }\end{array}$ \\
\hline
\end{tabular}




\begin{tabular}{|c|c|c|c|}
\hline & pencatatan data & $\begin{array}{l}\text { pemanggilan dan } \\
\text { pemrosesan data } \\
\text { menjadi lebih } \\
\text { mudah. } \\
\text { 2. Memberikan } \\
\text { informasi yang } \\
\text { cepat dan tepat } \\
\text { sasaran }\end{array}$ & $\begin{array}{l}\text { 2. } \\
\text { Sistem } \\
\text { diharapkan dapat } \\
\text { mempersingkat } \\
\text { waktu dalam } \\
\text { membuat laporan } \\
\text { secara terotomatisasi } \\
\text { yang berupa laporan } \\
\text { data kayu, laporan } \\
\text { katalog produk IKM } \\
\text { via internet. }\end{array}$ \\
\hline Akurasi data & $\begin{array}{l}\text { Pengolahan } \\
\text { data masih } \\
\text { menggunakan } \\
\text { Aplikasi } \\
\text { wordprocessing } \\
\text { dan } \\
\text { spreadsheet } \\
\text { dimana aplikasi } \\
\text { tersebut tidak } \\
\text { bisa } \\
\text { mengantisipasi } \\
\text { redundansi } \\
\text { data }\end{array}$ & $\begin{array}{l}\text { Peningkatan } \\
\text { reliability dan } \\
\text { keamanan data } \\
\text { serta } \\
\text { mengantisipasi } \\
\text { redundansi dengan } \\
\text { penyimpanan dalam } \\
\text { suatu database dan } \\
\text { sistem backup data }\end{array}$ & $\begin{array}{l}\text { 1. adanya integrasi } \\
\text { data untuk semua } \\
\text { laporan di setiap } \\
\text { simpul dan data } \\
\text { disimpan dalam } \\
\text { basis data sehingga } \\
\text { pemrosesan dan } \\
\text { pemanggilan data } \\
\text { menjadi lebih } \\
\text { mudah. } \\
\text { Sistem diharapkan } \\
\text { pada setiap simpul } \\
\text { memiliki hak akses } \\
\text { oleh setiap admin } \\
\text { simpul, sehingga } \\
\text { tidak setiap orang } \\
\text { berhak untuk } \\
\text { mengelola semua } \\
\text { data dan } \\
\text { mempergunakan } \\
\text { secara leluasa. }\end{array}$ \\
\hline
\end{tabular}

Pada desain logika ini terdiri dari Rancangan Data Flow Diagram dan Rancangan Entity Relational Diagram.

\section{Data Flow Diagram}

Data Flow Diagram (DFD) digunakan untuk menggambarkan proses-proses yang terjadi pada sistem yang akan dikembangkan. Dengan model ini, data-data yang terlibat pada masing-masing proses dapat diidentifikasi yang nantinya akan memberikan gambaran bagaimana sistem yang diusulkan 


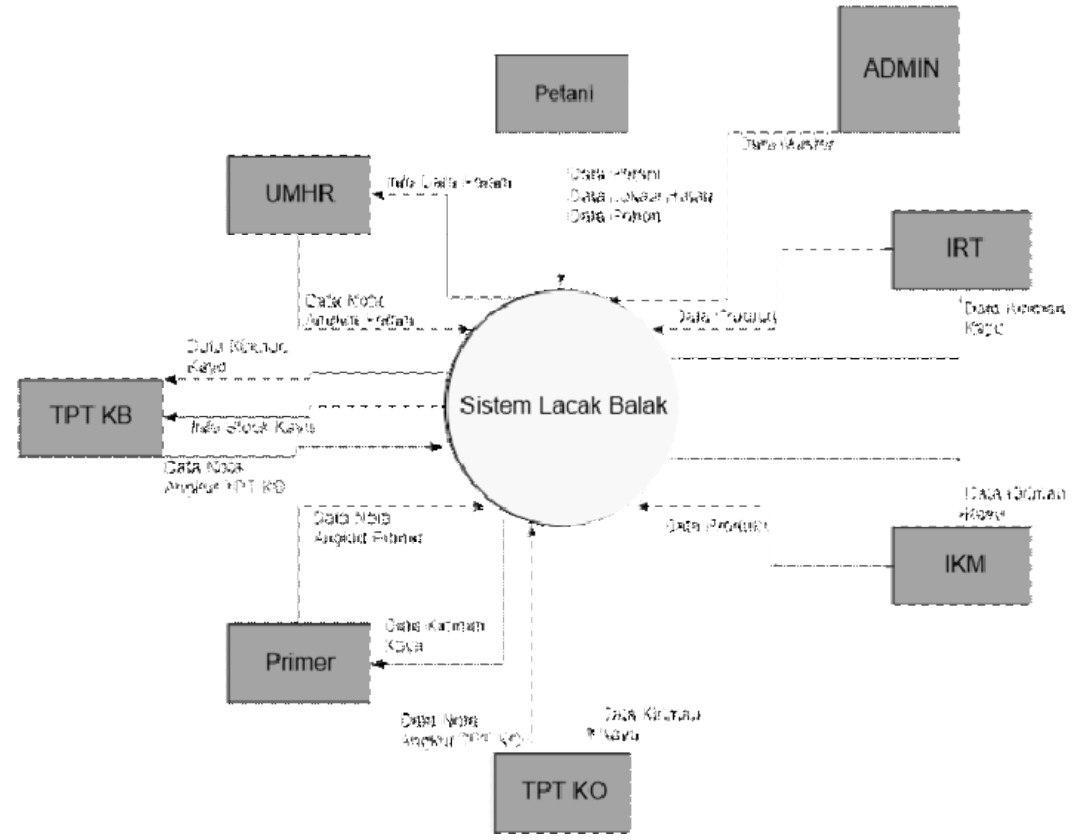

Gambar 5. Diagram Konteks Sistem Lacak Balak

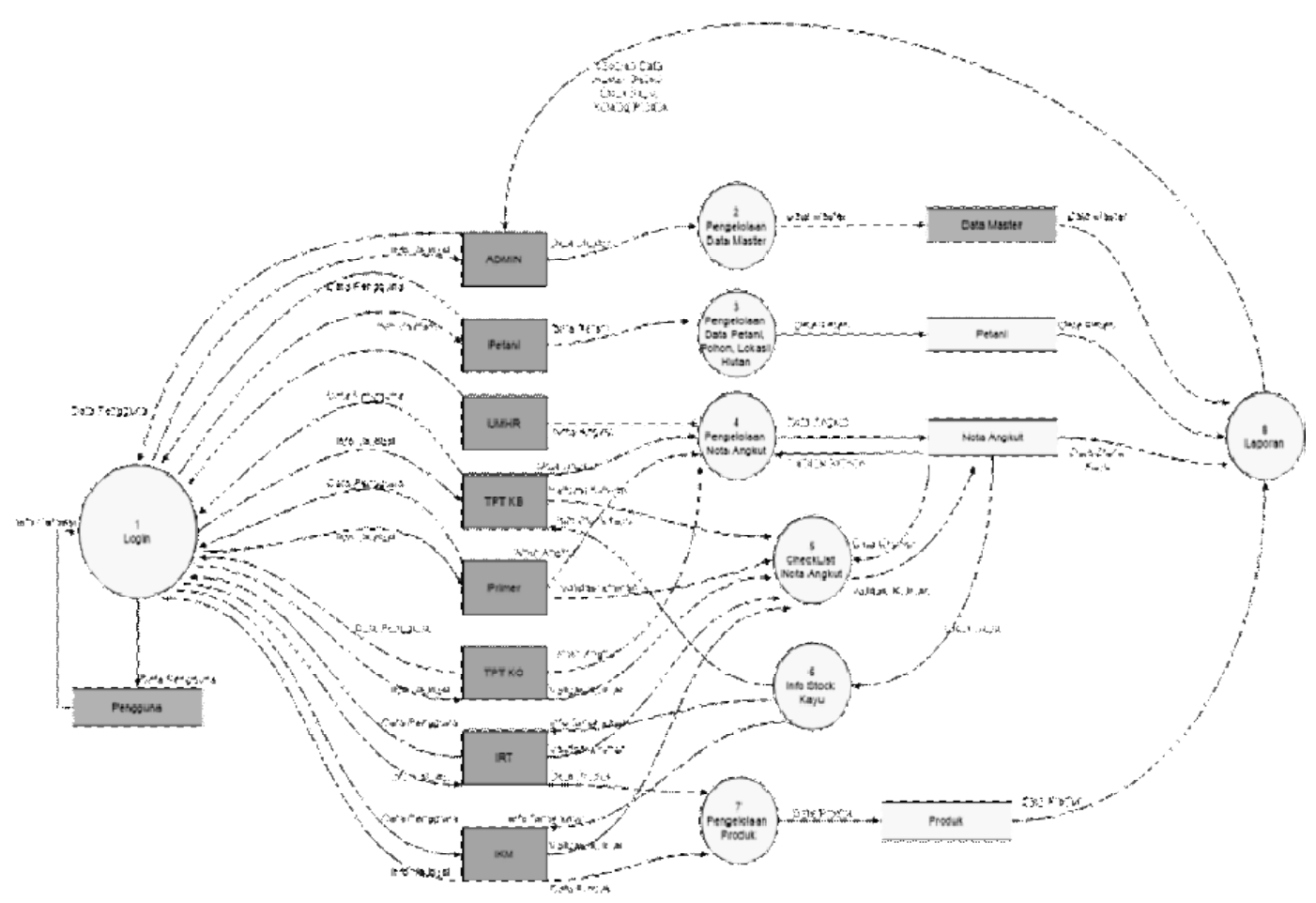

Gambar 6. DFD Level 1 Sistem Lacak Balak

\section{Alur Verifikasi Lacak Balak}

Alur verifikasi lacak balak terjadi pada setiap simpul / stakeholder, dimana setiap simpul memiliki kode khusus sebagai primary key yang membedakan antara satu dengan yang lainnya. Kode tersebut melekat pada setiap dokumen ketika terjadi transaksi pada setiap simpul. Bahkan ketika terjadi proses perubahan bentuk akibat pengolahan kayu, kode tersebut 
tetap melekat sehingga sangat mudah untuk melakukan pelacakan asal kayu dengan menggunakan sistem lacak balak. Hasil akhir dari proses lacak balak berupa QRcode. QRcode ini dapat dibaca dengan menggunakan gadget yang memiliki aplikasi QRcode Reader yang secara otomatis menampilkan alamat web yang akan menampilkan detail verifikasi dan asal kayu.

\section{Uji Coba}

Sistem Lacak Balak - LEI - Lembaga Ekolabel Indonesia

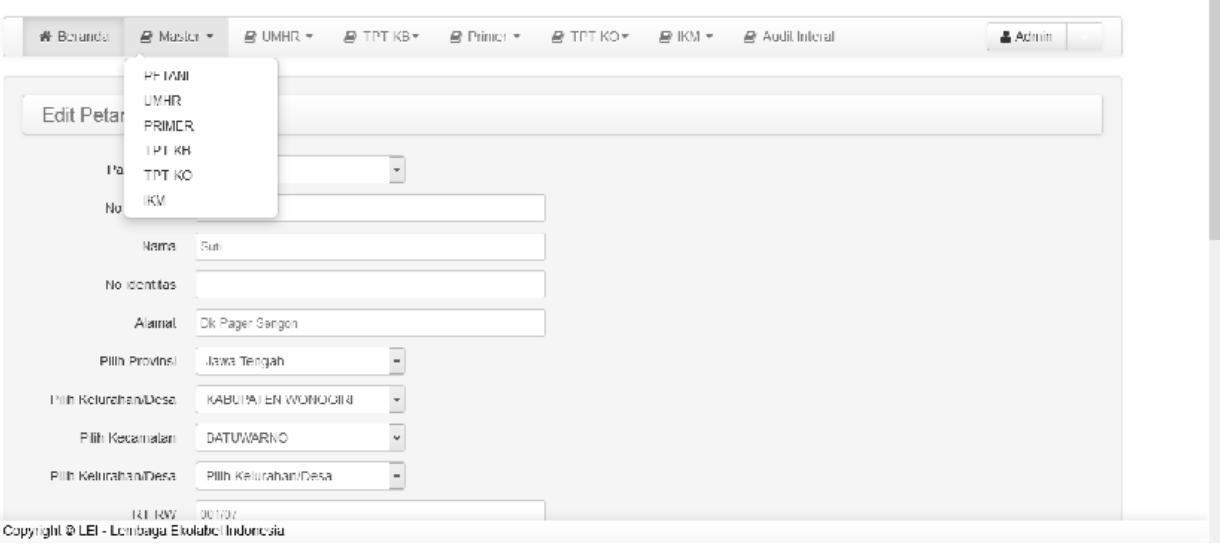

Gambar 7. Data Master

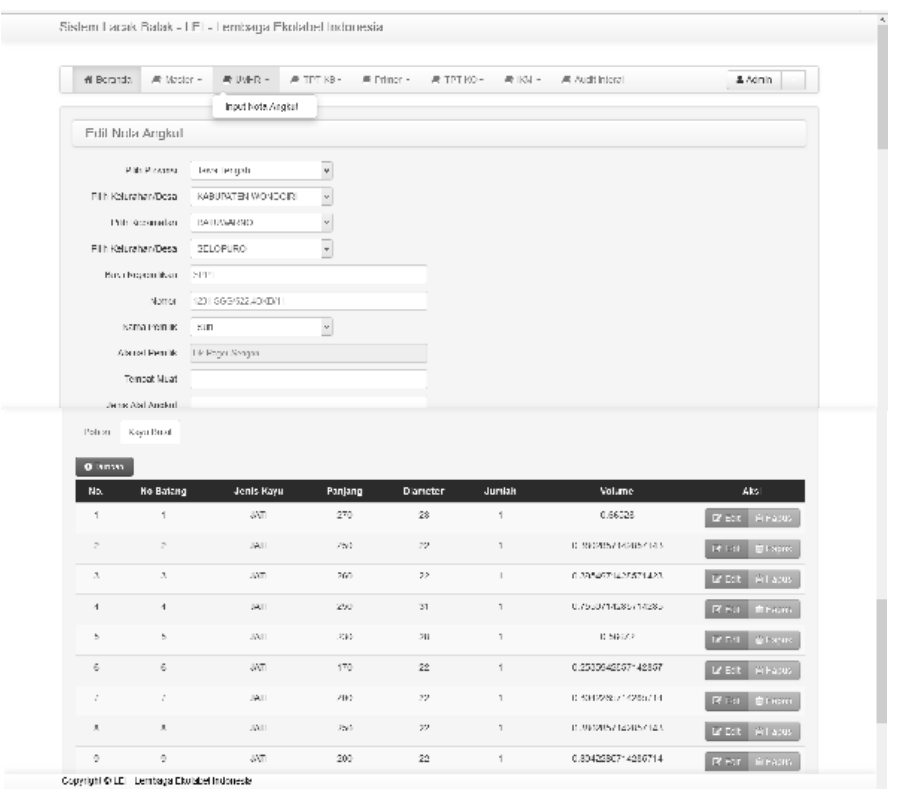

Gambar 8. Input Nota Angkut 


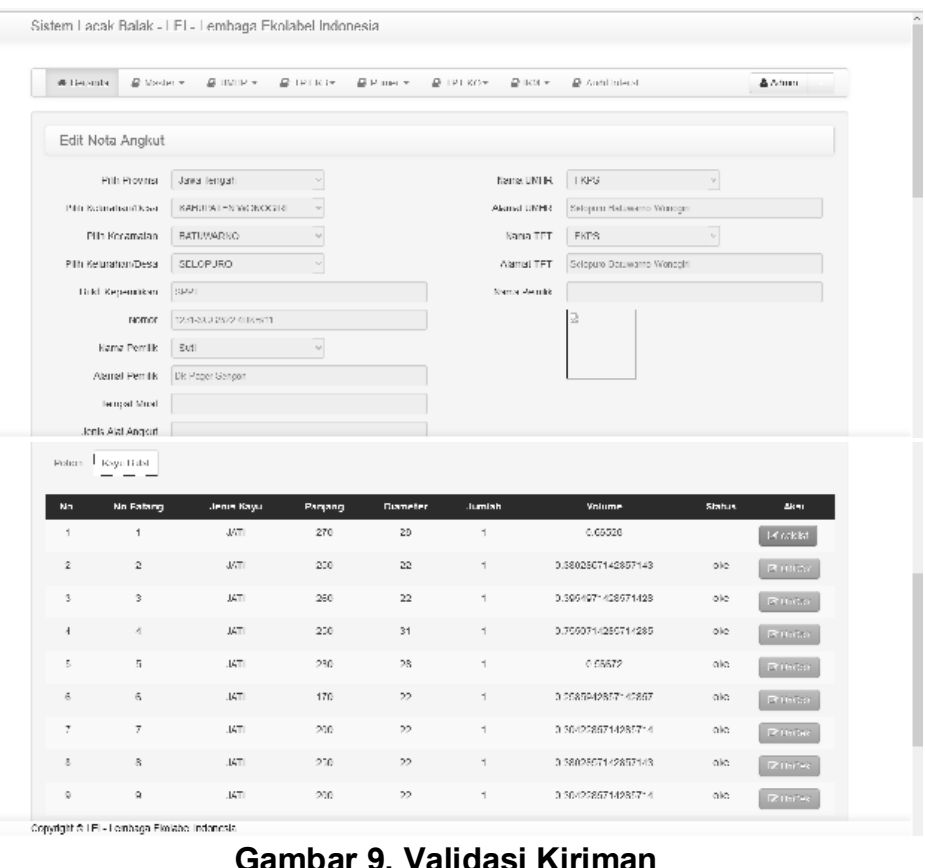

Gambar 9. Validasi Kiriman

Sistem Lacak Balak - LEI - Lembaga Ekolabel Indonesia

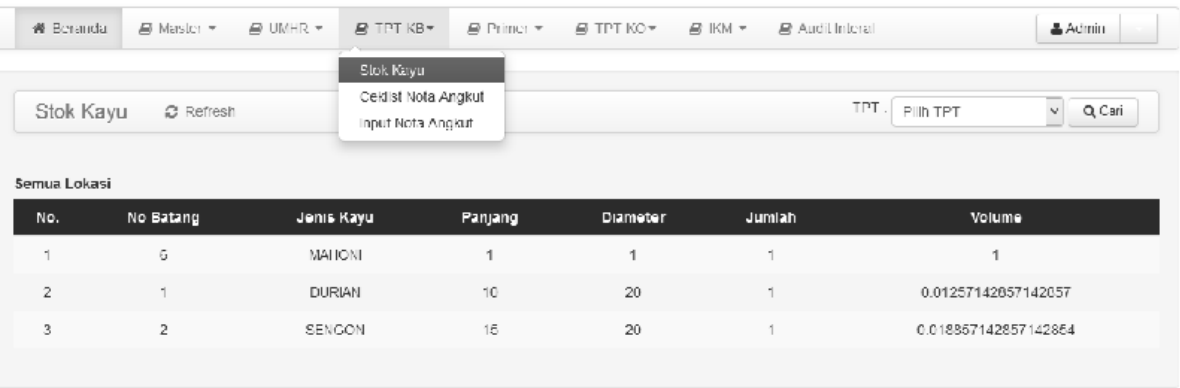




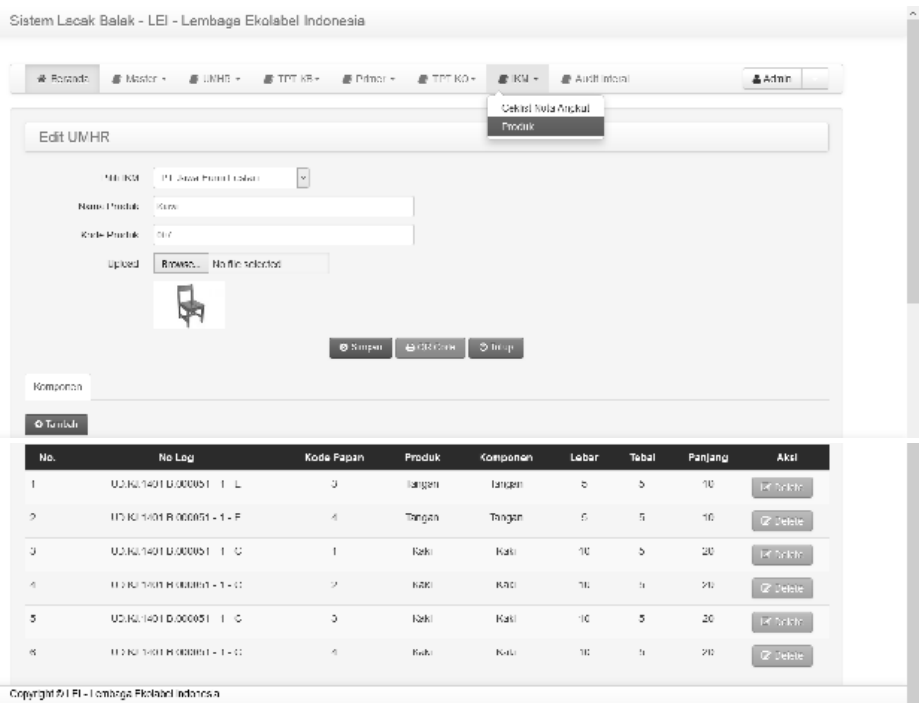

Gambar 11. Produk

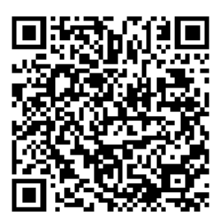

Gambar 12. Qrcode Produk

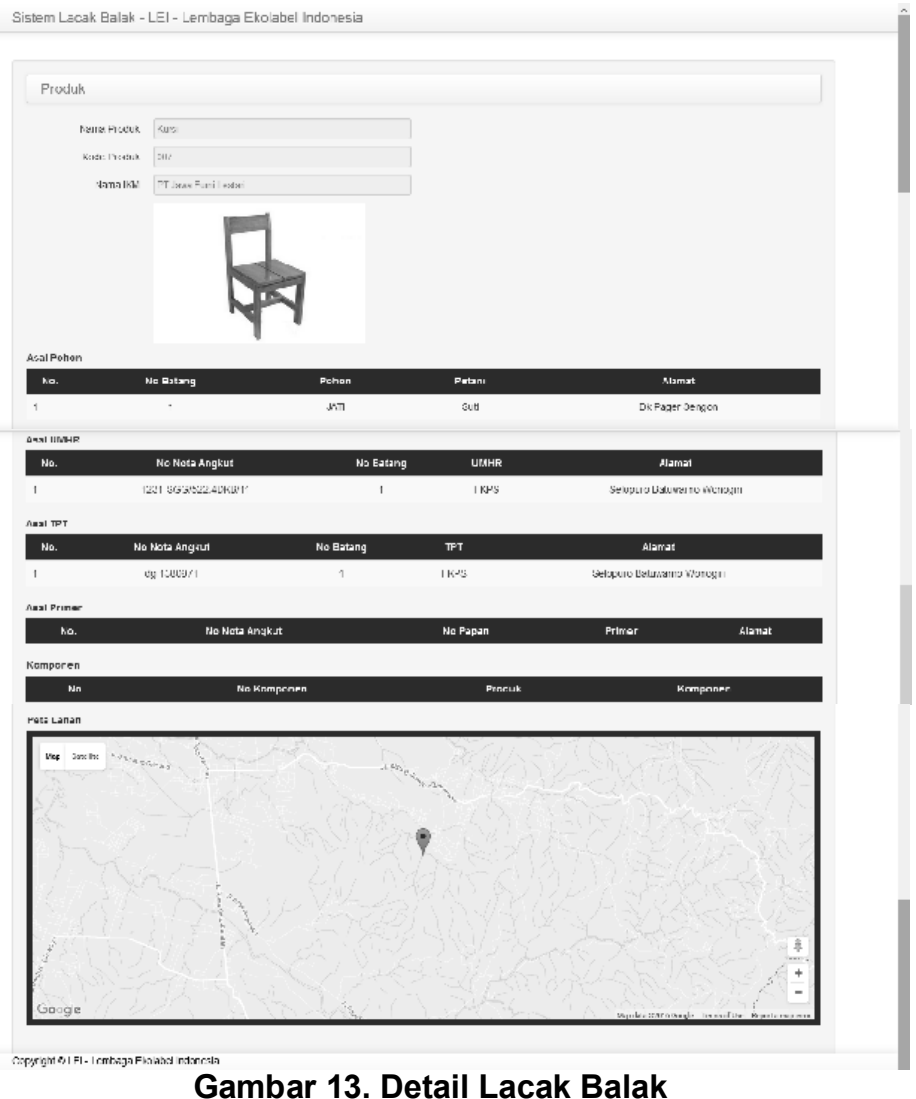

Sistem Informasi... (Yohanes $P$ ) 


\section{KESIMPULAN}

Berdasarkan pembahasan yang telah dikemukakan sebelumnya dalam, maka penulis menarik kesimpulan, yaitu:

1. Sistem Lacak Balak ini tidak hanya mempermudah LEI untuk mengembangkan jaringan hutan rakyat serta Industri kecil-menengah dalam rangka menjalankan praktek legalitas dan pengelolaan hutan lestari tetapi juga membantu dalam memantau verifikasi kayu dalam mewujudkan kayu bersertifikasi untuk membantu IKM dalam memenuhi permintaan pasar. Sistem Lacak Balak ini juga dapat mengatasi kekurangan pasokan kayu dari hutan swasta / komunitas / hutan rakyat yang telah diverifikasi untuk industri kayu. Ini termasuk memperbesar peran organisasi masyarakat sipil dalam memfasilitasi hutan-hutan swasta dan industri kayu kecil menengah untuk menerapkan SVLK dan skema FLEGT VPA .

2. Sistem Lacak Balak ini juga mempermudah dalam menelusuri asal kayu dari hutan rakyat ke tunggul aslinya. Ini terjadi karena setiap simpul diwajibkan mencatat asal hutan di mana kayu-kayu yang dipanen. Akibatnya, dokumentasi kayu dapat dicatat dengan baik. Sistem Lacak balak membuat jelas dan transparan rantai kayu dari hutan rakyat ke industri.

3. Dengan adanya sistem login berdasarkan simpul, Sistem Lacak Balak dapat membatasi orang yang berhak untuk mengelola semua data dan mempergunakan data. Sehingga data lacak balak menjadi lebih reliable serta dapat mengantisipasi redundansi data.

\section{DAFTAR PUSTAKA}

Abdullah, Achmad Syarif, Hadi Setiawan, Nurul Ummi. (2013)Perancangan Sistem Informasi Berbasis Website dengan Metode Framework For The Applications of System Thinking. Jurnal Teknik Industri, Vol.1, No.4, Desember 2013, pp.358-367.

Al Fatta Hanif. Analisis dan Perancangan Sistem Informasi. Yogyakarta : penerbit ANDI, 2007

G. Giova, "Improving Chain of Custody in Forensic Investigation of Electronic Digital Systems," Int. J. Comput. Sci. Netw. Secur., vol. 11, no. 1, pp. 1-9, 2011. [1]

J. Ćosić, Z. Ćosić, M. Bača, J. Cosic, G. Cosic, and M. Baca, "An Ontological Approach to Study and Manage Digital Chain of Custody of Digital Evidence," JIOS, vol. 35, no. 1, pp. 1-13, 2011. [2]

Prayudi, Y,Y.2013. Chain of Custody. https://catatanforensikadigital.wordpress.com/2013/11/14/chain-of-custody/.

22 November 2016 [3]

Jogiyanto HM. Analisis dan Disain . Yogyakarta : penerbit ANDI, 2005

Kadir Abdul. Pengenalan Sistem Informasi. Yogyakarta : penerbit ANDI, 2003

Kristanto Andri. Perancangan Sistem Informasi dan Aplikasinya. Yogyakarta : penerbit Gava Media, 2008

Stair, Ralph \& Reynolds, George., 2010. Principles Information Systems. 9th ed. Course Technology Cengange Learning.

Whitten, Jeffery. 2004. Metode Desain dan Analisis Sistem Edisi ke 6. Yogyakarta : Penerbit Andi

Sutanta Edhy. Sistem Informasi Manajemen. Yogyakarta : penerbit Graha IImu, 2003 